\title{
Identification of cis- and trans-acting elements regulating calretinin expression in mesothelioma cells
}

\author{
Jelena Kresoja-Rakic ${ }^{1}$, Esra Kapaklikaya ${ }^{1}$, Gabriela Ziltener $^{1}$, Damian Dalcher ${ }^{2}$, \\ Raffaella Santoro ${ }^{2}$, Brock C. Christensen ${ }^{3}$, Kevin C. Johnson ${ }^{3}$, Beat Schwaller ${ }^{4}$, \\ Walter Weder ${ }^{5}$, Rolf A. Stahel ${ }^{1}$, Emanuela Felley-Bosco ${ }^{1}$ \\ 'Laboratory of Molecular Oncology, Clinic of Oncology, University Hospital Zürich, Zürich, Switzerland \\ ${ }^{2}$ Institute of Veterinary Biochemistry and Molecular Biology, University of Zürich, Zürich, Switzerland \\ ${ }^{3}$ Departments of Epidemiology, Pharmacology and Toxicology and Community and Family Medicine, Geisel School of Medicine \\ at Dartmouth, Hanover, NH, USA \\ ${ }^{4}$ Anatomy, Department of Medicine, University of Fribourg, Fribourg, Switzerland \\ ${ }^{5}$ Division of Thoracic Surgery, University Hospital Zürich, Zürich, Switzerland
}

Correspondence to: Emanuela Felley-Bosco, e-mail: emanuela.felley-bosco@usz.ch

Keywords: malignant pleural mesothelioma, calretinin, promoter, NRF-1, cell-cycle regulated expression

Received: September 08, 2015

Accepted: January 18, 2016

Published: February 01, 2016

\section{ABSTRACT}

Calretinin (CALB2) is a diagnostic marker for epithelioid mesothelioma. It is also a prognostic marker since patients with tumors expressing high calretinin levels have better overall survival. Silencing of calretinin decreases viability of epithelioid mesothelioma cells. Our aim was to elucidate mechanisms regulating calretinin expression in mesothelioma. Analysis of calretinin transcript and protein suggested a control at the mRNA level. Treatment with 5-aza-2'-deoxycytidine and analysis of TCGA data indicated that promoter methylation is not likely to be involved. Therefore, we investigated CALB2 promoter by analyzing $\sim 1 \mathrm{~kb}$ of genomic sequence surrounding the transcription start site (TSS) +1 using promoter reporter assay. Deletion analysis of CALB2 proximal promoter showed that sequence spanning the $-161 /+80 \mathrm{bp}$ region sustained transcriptional activity. Site-directed analysis identified important cis-regulatory elements within this $-161 /+80$ bp CALB2 promoter. EMSA and ChIP assays confirmed binding of NRF-1 and E2F2 to the CALB2 promoter and siRNA knockdown of NRF-1 led to decreased expression of calretinin. Cell synchronization experiment showed that calretinin expression was cell cycle regulated with a peak of expression at G1/S phase. This study provides the first insight in the regulation of CALB2 expression in mesothelioma cells.

\section{INTRODUCTION}

Malignant pleural mesothelioma (MPM) are tumors originating from the surface serosal cells of the pleura [1]. With the established standard of care, i.e. pemetrexed with platinum-based chemotherapy, MPM patients have a median survival of one year [2], therefore it is important to better understand the biology of mesothelioma development that would allow for designing and developing novel and more effective therapy strategies.

Calretinin (CR, gene CALB2) is a $30 \mathrm{kDa}$ calciumbinding protein belonging to the EF-hand family [3]. In 1996, Doglioni et al demonstrated specificity of calretinin immunoreactivity in mesothelioma compared to other tumor types [4]. Currently, calretinin is the most commonly used diagnostic mesothelioma marker [5]. Reactive mesothelial cells and malignant mesothelioma cells show nuclear and cytosolic calretinin staining allowing differentiation of mesothelioma from adenocarcinoma [6]. MPM can be categorized into three groups based on the histological characteristics: epithelial, biphasic and sarcomatoid characterized by strong, intermediate and weak (absent) calretinin immunoreactivity, respectively [7] . Three independent studies suggested that calretinin can be also utilized as a prognostic marker since strong calretinin immunostaining correlated with improved survival [7-9].

In two epithelioid mesothelioma cell lines, downregulation of calretinin by a lentiviral short hairpin 
approach impaired cell proliferation and triggered apoptosis via the intrinsic caspase-9-dependent pathway [10] suggesting that calretinin is important for epithelioid mesothelioma cell survival.

Calretinin is physiologically expressed in different neuronal cell populations, e.g. in the retina and the cerebellum [11] as well as in Leydig cells, Sertoli cells and adipocytes [5]. Little is known about the mechanisms regulating calretinin expression in various tissues or in cancer. It has been reported that the mouse Calb2 and human $C A L B 2$ promoter region contain TATA and CAAT boxes [12]. A mouse Calb2 promoter fragment $(-115 /+54 \mathrm{bp})$ was shown to be active in neuronal and cancer cells $[13,14]$. In human colon cancer cells, calretinin expression is downregulated by butyrate, a substance that induces cell differentiation [15]. Butyrateinduced calretinin downregulation is mediated through butyrate dependent repressive elements which are not operational in mesothelioma cells [16].

In this study, our aim was to investigate and characterize transcriptional control of calretinin expression in mesothelioma cells.

\section{RESULTS}

\section{Calretinin protein levels correlate with $C A L B 2$ transcript levels across a panel of different mesothelioma cell lines}

To characterize calretinin expression, we assessed mRNA and protein levels across a panel consisting of 11 mesothelioma cell lines, one SV-40 immortalized human pleural mesothelial cell line (MeT5A) and HEK293 cells (Figure 1A and 1B). Five cell lines were of epithelioid type (NCI-H226, ACC-MESO-4, ZL55, MERO-84, and ZL5), four were biphasic (MSTO-211H, MERO-82, MERO-83, SPC111) and two were sarcomatoid (ZL34 and ONE58). Levels of CALB2 transcript were significantly higher $(p=0.0285)$ in epithelioid histotype. Calretinin was also expressed in HEK293 cells, which might be expected since HEK293 cells are of kidney embryonic origin [17] and both kidney and mesothelium originate from the mesoderm. Importantly, CALB2 mRNA expression was strongly positively $(p=0.0002)$ correlated with calretinin protein levels (Figure 1C), suggesting that calretinin expression could be regulated either through copy number variation or through control of mRNA levels.

\section{Calretinin promoter is not inhibited by DNA methylation in mesothelioma cell lines and tumor samples}

Analysis of genomic copy number abnormalities (CNA) in mesothelioma, using arrayMap [18] showed no indications of genetic alteration in CALB2 gene (Supplementary Figure 1) while a study has described loss at 16q22 in two out of 18 mesothelioma cases [19], indicating that upregulation of calretinin expression in mesothelioma is not linked to increased gene copy number.

We then took advantage of the known differential expression of calretinin between epithelioid and sarcomatoid mesothelioma to explore whether this might represent a hint that calretinin expression is controlled by methylation of the promoter, since this mechanism controls the expression of several genes in MPM [20]. A putative $C A L B 2$ proximal promoter region was defined based on two criteria: the observation that most human promoters are found between -800 upstream and +200 bp downstream of putative transcription start site (TSS; +1) [21] and according to publicly available data on high throughput ChIP data reported in the UCSC browser (Supplementary Figure 2). In silico analysis (http://www.bioinformatics.org/sms2/cpg_islands.html) of the $-838 /+80$ bp region of $C A L B 2$ promoter using the method defined by Gardiner-Garden [22], documented the presence of $\mathrm{CpG}$ islands and a high $\mathrm{GC}$ content starting from 338bp upstream of the TSS. Inactivation of gene expression by methylation of $\mathrm{CpG}$ islands present in promoters is a common epigenetic mechanism in health and diseases [23]. Therefore, to test the hypothesis that calretinin expression might be partly driven by epigenetic mechanisms, ZL55 (high-calretinin, epithelioid) and SPC111 (low-calretinin, biphasic) cells were treated for seven days with the hypomethylating agent 5-aza-2'deoxycytidine (5-Aza-CdR) at 100 and $250 \mathrm{nM}$ and the expression of calretinin was evaluated. The expression of two cancer-associated testis antigens $C T A G 1 B$ and $M A G E-C 1$ genes was used as a positive control, since their promoters are known to be controlled by DNA methylation [24]. Although the expression of CTAG1B and $M A G E-C 1$ mRNA was strongly enhanced by 5-AzaCdR treatment in SPC111 and ZL55 cells (Figure 2A), the expression of calretinin mRNA and protein (Figure 2A and 2B) did not increase. On the contrary, treatment with 5 -Aza-CdR resulted in a decrease in calretinin protein levels, especially in SPC111 cells. Moreover, the methylation status of nine $\mathrm{CpG}$ sites in the CALB2 promoter of epithelioid $(n=57)$ and biphasic $(n=23)$ mesothelioma samples from The Cancer Genome Atlas (TCGA) database generally showed low methylation levels, particularly at $\mathrm{CpG}$ sites nearest to the TSS (Figure 2C). CALB2 promoter $\mathrm{CpG}$ methylation was not significantly negatively correlated with $C A L B 2$ gene expression in epithelioid or biphasic tumors (Table 1). As control, the methylation status of $M A G E C 1$ promoter was also investigated. The region of the $M A G E C 1$ promoter exhibits high levels of methylation (Supplementary Figure 3) and the gene is lowly expressed in TCGA mesothelioma tumors. Importantly, several of the CpGs located at or near the transcriptional start site are significantly negatively correlated with gene expression (Supplementary Table 2) and the gene is lowly expressed 
in both biphasic and epithelioid tumors. The high levels of DNA methylation and low levels of expression coupled with our experimental evidence of reactivation of gene expression with treatment with hypomethylating agents suggest that $M A G E C 1$ serves as an appropriate control gene in our study. Taken together, our data suggest that promoter methylation is not driving differential expression of calretinin between mesothelioma histotypes.

\section{The $-161 /+80$ bp $C A L B 2$ promoter region drives expression of luciferase reporter in mesothelioma cells}

We then investigated the activity of the CALB2 promoter to define cis-regulatory sequences important for calretinin expression. Four 5'-deletion promoter fragments $(-838,-419,-264,-161 \mathrm{bp}$ upstream and $+80 \mathrm{bp}$ downstream of TSS +1) were cloned into the firefly

A

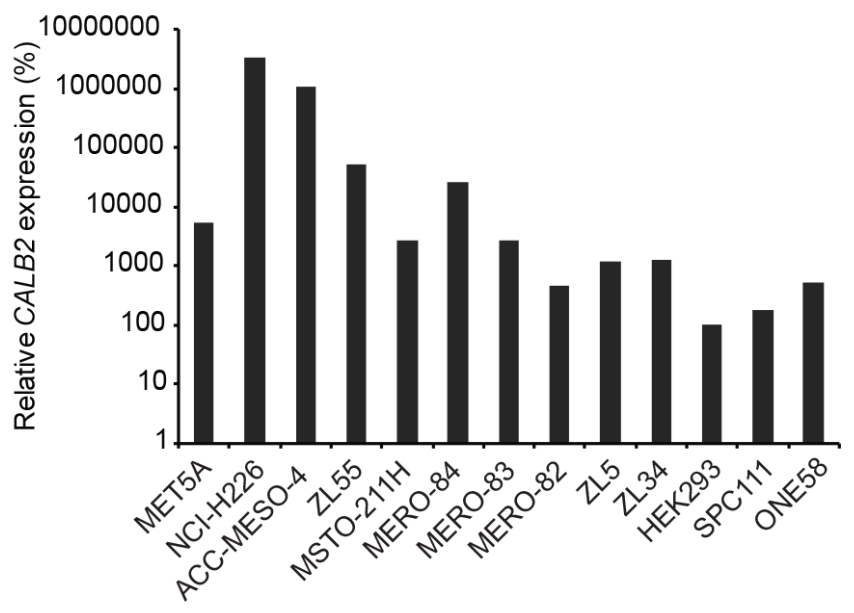

B

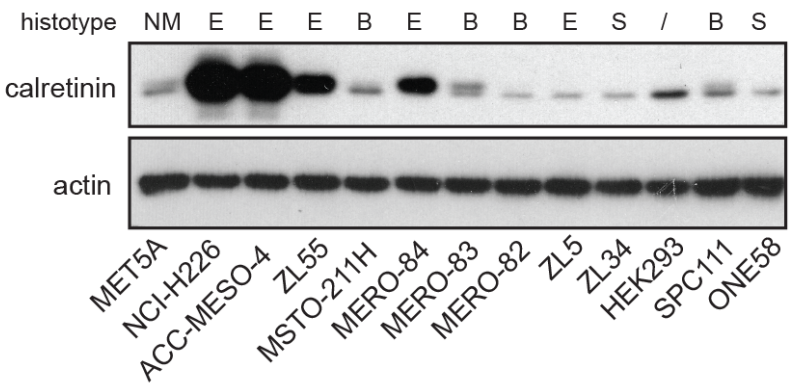

C

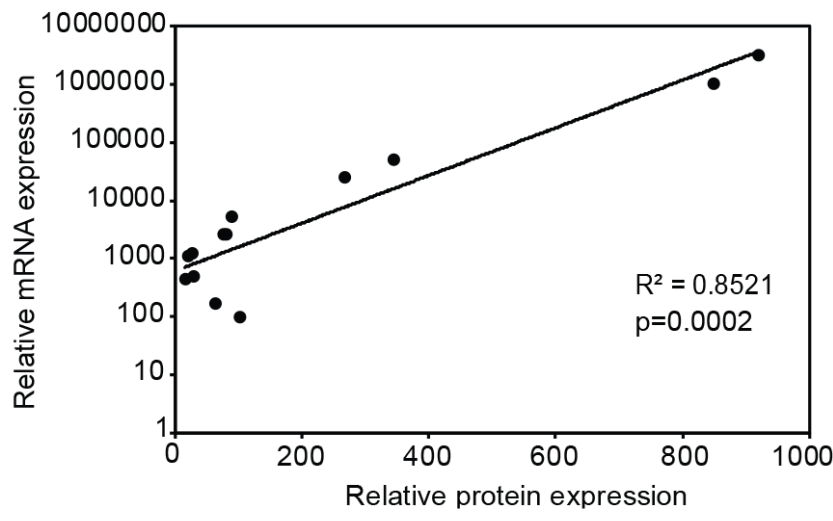

Figure 1: Differential expression of calretinin in a panel of 13 cell lines. (A) Quantitative RT-PCR analysis of $C A L B 2$ expression in 11 mesothelioma cell lines, one immortalized mesothelial cell line (MET5A) and HEK293 cells using histones as an internal control. Levels are shown relative to the HEK293 cells according to the $-\Delta \Delta \mathrm{Ct}$ method. (B) Western blot analysis of calretinin protein levels in the same panel of cell lines. Actin was used as loading control. (C) Relative mRNA levels are plotted against the relative protein levels; each dot represents a cell lines as in A and B. 
luciferase basic reporter pGL3-B (Figure 3A). To test transcriptional activity of the promoter constructs, NCI-H226, Z155, SPC111 and ONE58 cells were transiently transfected with the promoter constructs along with the pRL-TK plasmid as an internal control. The shortest $-161 /+80$ bp CALB2 promoter construct appeared to be as active as the other longer sequences in all tested cell lines (Figure 3B) defining this fragment as the minimal $C A L B 2$ promoter. The $240 \mathrm{bp}$ minimal promoter has more activity than any of the longer versions (Supplementary Figure 4) indicating the presence of negative regulators. In addition, $-161 /+80 \mathrm{bp} C A L B 2$ promoter activity was correlated ( $p=0.017$ ) with $C A L B 2$ expression (Figure 3C) with the lowest transcriptional activity observed in ONE58 cells which express extremely low levels of calretinin, and the highest transcriptional activity in NCI-H226 cells, expressing the highest levels of calretinin. Since the $-161 /+80$ bp fragment was sufficient to drive reporter expression in the tested mesothelioma cells, the next step was to further characterize its cis-regulatory elements.

\section{Mutation of E2F2/NRF-1-like site strongly reduced promoter activity}

To search for putative protein binding sites, in silico analysis was performed on the sequence from $-161 \mathrm{bp}$ to +80 bp of the $C A L B 2$ promoter using MatInspector software [25]. Most frequently identified binding sites were the ones for NRF-1 (nuclear respiratory factor 1), as well as for E2F family members and CREB (cAMP

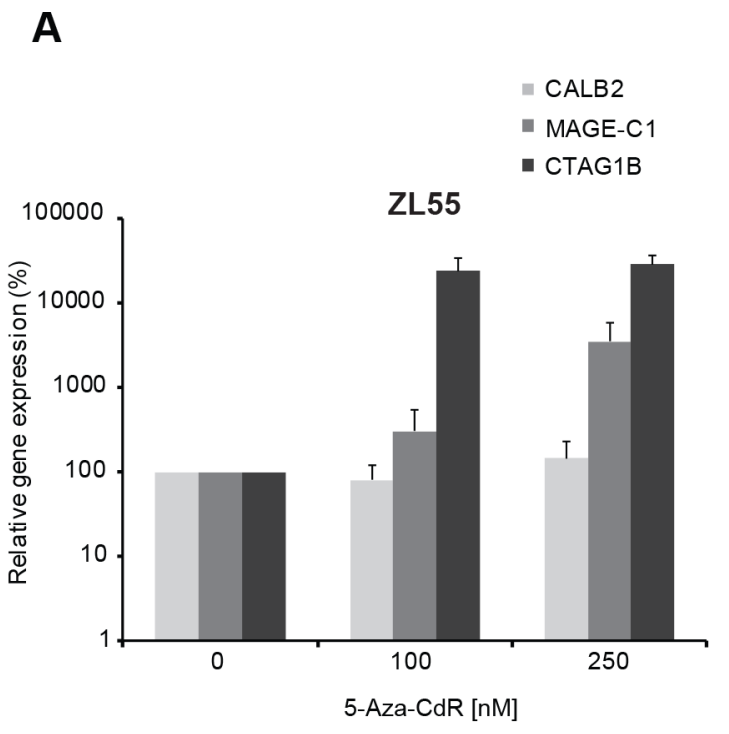

B

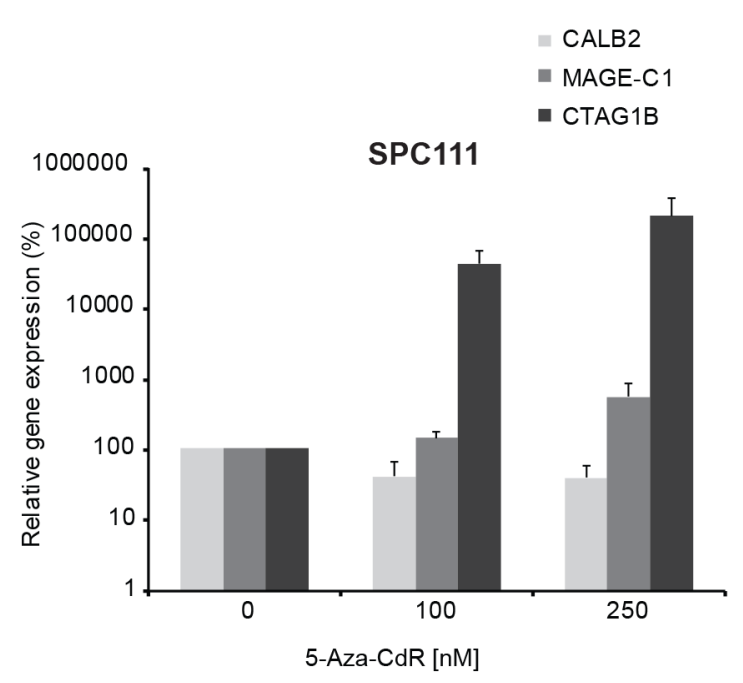

C
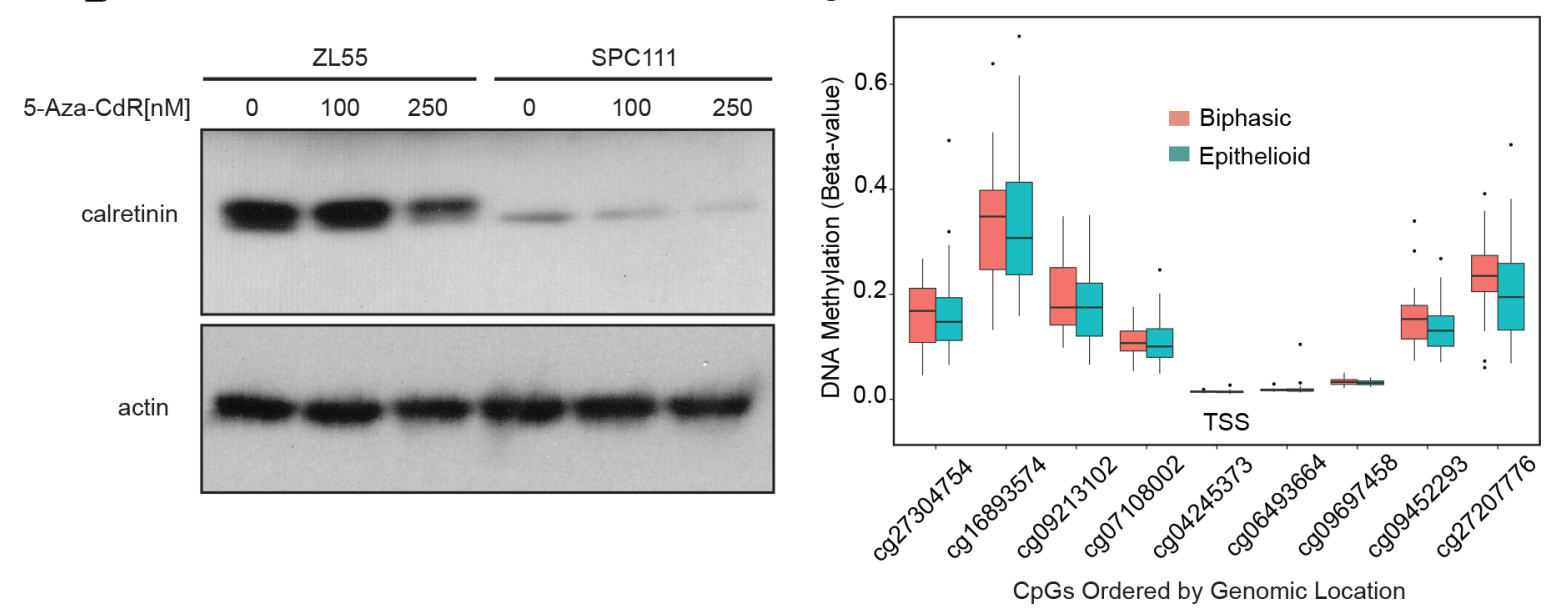

Figure 2: Promoter methylation does not regulate calretinin expression in cell lines and tumor samples. (A) ZL55 and SPC111 cells were treated for 7 days with the hypomethylating agent 5-Aza-CdR (100 nM and $250 \mathrm{nM})$. Analysis of mRNA showed no change in $C A L B 2$ expression but strong upregulation of $M A G E-C 1$ and $C T A G 1 B$ expression. Mea $\pm \pm \mathrm{SD}, n=3$. (B) Calretinin protein levels decreased upon 5-Aza-CdR treatment in both ZL55 and SPC111 cells. Representative of three independent experiments. (C) CpG sites in the promoter region of CALB2 from the Illumina HumanMethylation450 array are shown in $5^{\prime}$ to $3^{\prime}$ order versus methylation betavalue which represents the percent methylation of the sample. Mesotheliomas are stratified by tumor histology, epithelioid $(n=57)$, and biphasic $(n=23)$. 
Table 1: Correlation between $C A L B 2$ gene promoter $\mathrm{CpG}$ methylation and $C A L B 2$ expression (*Spearman's test)

\begin{tabular}{|c|c|c|c|c|c|c|}
\hline cgID & Chromosome & Position & $\begin{array}{l}\text { Epithelioid } \\
\text { Correlation }\end{array}$ & Epithelioid $P$-value* & $\begin{array}{l}\text { Biphasic } \\
\text { Correlation }\end{array}$ & $\begin{array}{l}\text { Biphasic } \\
P \text {-value* }\end{array}$ \\
\hline $\operatorname{cg} 27304754$ & 16 & 71392088 & 0.12 & 0.385 & 0.45 & 0.034 \\
\hline $\operatorname{cg} 16893574$ & 16 & 71392095 & -0.14 & 0.296 & 0.42 & 0.047 \\
\hline $\operatorname{cg} 09213102$ & 16 & 71392373 & -0.14 & 0.312 & 0.35 & 0.122 \\
\hline $\operatorname{cg} 07108002$ & 16 & 71392377 & -0.24 & 0.068 & 0.23 & 0.285 \\
\hline $\operatorname{cg} 04245373$ & 16 & 71392615 & 0.02 & 0.893 & -0.26 & 0.223 \\
\hline $\operatorname{cg} 06493664$ & 16 & 71392628 & 0.04 & 0.749 & -0.41 & 0.053 \\
\hline $\operatorname{cg} 09697458$ & 16 & 71392748 & -0.09 & 0.502 & 0.05 & 0.823 \\
\hline $\operatorname{cg} 09452293$ & 16 & 71392838 & -0.16 & 0.230 & 0.05 & 0.823 \\
\hline $\operatorname{cg} 27207776$ & 16 & 71393801 & -0.25 & 0.063 & -0.07 & 0.740 \\
\hline
\end{tabular}

response element binding protein) (Figure 4A). The activation of the latter has been observed in vitro after exposure of mesothelial cells to asbestos [26]. Promoter constructs containing selective mutations were created using a site-directed mutagenesis approach (Figure 4B) and their transcriptional activity was measured in ZL55 and SPC111 cells. All mutated promoter constructs showed significantly decreased transcriptional activity compared to the control construct in both cell lines (Figure 4C). The transcriptional activity of the E2F2/NRF1 (-64)-like mutant resulted in a $80 \%$ decrease compared to the wild-type promoter sequence suggesting that E2F2 or NRF-1 might be important for the transcriptional control of calretinin expression. A strongly reduced activity of the E2F2/NRF-1 mutant construct was also observed in HEK293 cells (Supplementary Figure 5), indicating that this transcriptional control is not restricted to mesothelioma cells, but possibly to other cells of mesodermal origin.

\section{In vitro and in situ binding of NRF-1 and E2F2 to E2F2/NRF-1-like binding motif in the $C A L B 2$ promoter}

Alignment of the CALB2 promoter ortholog nucleotide sequences (Supplementary Figure 6) revealed that the stretch containing the putative binding sites for E2F2 or NRF-1 ( -75 to $-51 \mathrm{bp}$ ) shows the highest degree of identity across various species (Figure 5A). Therefore, to experimentally demonstrate potential functionally relevant binding of E2F2 or NRF-1, an EMSA assay was performed using biotin labeled 25-bp oligonucleotide containing the putative E2F2/NRF-1 binding site (Figure 5B). Upon incubation of ZL55 nuclear extract with the specific labeled probe, DNA-protein complexes $\mathrm{C} 1, \mathrm{C} 2$ and $\mathrm{C} 3$ were formed (Figure 5B, lane 2). All three
DNA-protein complexes were diminished with increasing amounts of unlabeled competitor (Figure 5B, lane 3 and 4) but were not outcompeted using an unrelated oligo competitor (data not shown). However, in the reaction with mutated competitor, the $\mathrm{C} 3$ complex was detected again but not the complexes $\mathrm{C} 1$ and $\mathrm{C} 2$ (Figure 5B, lane 5). Addition of a specific antibody against NRF-1 resulted in the appearance of a heavier complex (Figure 5B, lane 6) and a decrease of the $\mathrm{C} 2$ complex, while no change was observed with an anti-E2F2 antibody (Figure 5B, lane 7).

To confirm in situ in cultured cells the presence of NRF-1 or E2F2 on the CALB2 promoter, chromatin immunoprecipitation assay (ChIP) was performed in ZL55 cells with antibodies against NRF-1 and E2F2. The promoter of $C D C 25 \mathrm{~A}$ gene, a known E2F target [27] lacking a binding site for NRF-1, was used as a negative control for NRF-1 and as a positive control for E2F2. Chromatin immunoprecipitation assay showed that compared to $C D C 25 A$, NRF-1 was significantly enriched in $C A L B 2$ promoter whereas E2F2 bound to both, $C D C 25 A$ and $C A L B 2$ promoters (Figure 5C). These data demonstrate that NRF-1 and E2F2 are able to bind to $C A L B 2$ promoter.

NRF-1 expression levels are likely not responsible for differences in calretinin expression levels observed in the various MPM lines since NRF-1 levels were rather homogenous in the tested cell lines (Figure 5D). However, silencing of NRF-1 resulted in calretinin downregulation in SPC111 cells (Figure 5E and Supplementary Figure 7). Taken together, these data provide evidence that NRF-1 is an important positive regulator for calretinin expression.

\section{Calretinin expression is cell cycle-dependent}

Besides NRF-1, members of the E2F family were among the most frequently identified putative transcription factors binding to the $-161 /+80 \mathrm{bp} C A L B 2$ promoter 
region and E2F2 binding was detected by ChIP analysis. Since E2F family members regulate cell cycle-dependent expression of many genes [28], we hypothesized that calretinin expression might be regulated in a cell cycledependent manner. To investigate the kinetics of calretinin expression, ZL55 and SPC111 cell were exposed to double thymidine treatment followed by nocodazole treatment, after which calretinin expression was assessed at different time points (Figure 6A and 6B). The progression through the cell cycle was monitored by flow cytometry analysis (data not shown), while the expression pattern of cyclin A and cyclin E (Figure 6A) served to document the transition of cells from G1/S to M phase [29, 30]. Double thymidine treatment synchronized the majority of cells at the G1/S transition, where high levels of calretinin expression were observed (Figure 6A). Calretinin expression then significantly decreased $5 \mathrm{~h}$ after thymidine removal when the majority of cells were in the G2/M phase. The same

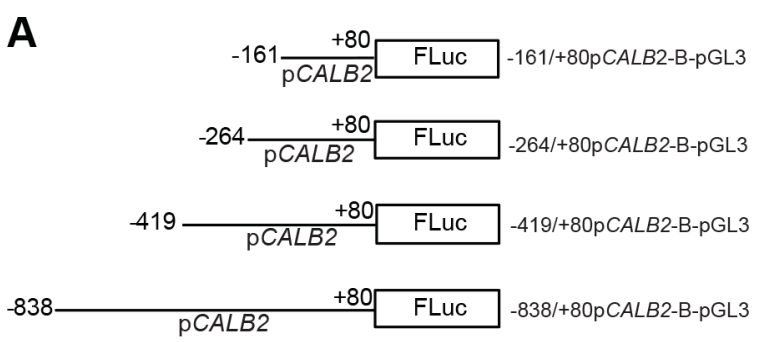

\section{B}
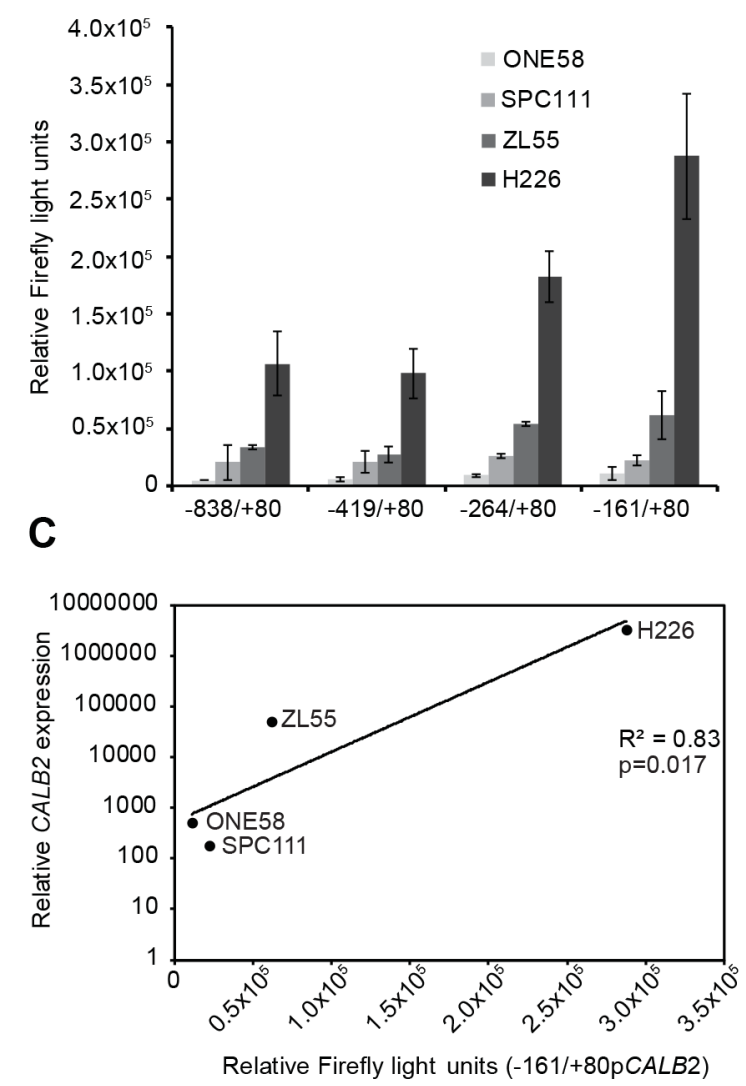

Figure 3: Transcriptional activity of the minimal $C A L B 2$ promoter is proportional to calretinin expression. Transcriptional activity of different promoter constructs was assessed by transient transfection and dual luciferase assay using pTK-RL as an internal control. (A) 5'-deletion constructs of the CALB2 promoter engineered in the pGL3-basic (pGL3-B) luciferase reporter plasmid. Lines represent $C A L B 2$ promoter fragment; the name and the size are indicated by nucleotide position upstream $(-)$ or downstream $(+)$ relative to the transcription start site $(+1)$. (B) CALB2 promoter activity in ONE58, SPC111, ZL55 and NCI-H226 cells, which express different levels of calretinin. To allow for comparison of the absolute promoter activity between the cell lines, Firefly light units were multiplied by a correction factor that compensates for differences in the transfection efficacy. The correction factor was based upon the Renilla Light Units (ReLU) of the internal control, pTK-RL, and was calculated by dividing the mean ONE58 ReLU by the mean of ZL55, SPC111 and H226 ReLU for each construct. Mea $\pm \mathrm{SD}, n=3$. (C) Relative mRNA abundance is plotted versus the relative Firefly light units reflecting absolute $-161 /+80$ bp $C A L B 2$ activity for the indicated cell lines. 
A

-161 TCTCAGCGCAGAGGTAAGGGCCCTCTAGGAGTCCGGGCCGAGCCTCTCGCGCCGCCGCCCCCG E2F2(-69) E2F2/NRF-1(-64)

NRF-1 $(-41)$

-98 CCGCGCCGCGCCCCGGTCGGATTCCCTGAGCGCGCGCGCCCCCTTCTGGCGGCCGGGCGCAG NRF-1(-35) CREB $(-2) \stackrel{+1}{\longrightarrow}$

-36 GCGCAGGCTCCAGAGCGTATATAAGGGCAGCGTGGCGCACAACCCCAG CGCGAGTGCCAGAGC

+28 CCAGCCGGCGCGGAGCGGGAGCGGTGCAGGCTGAGGTCTCCGAGCGGCTCGCC +80

B
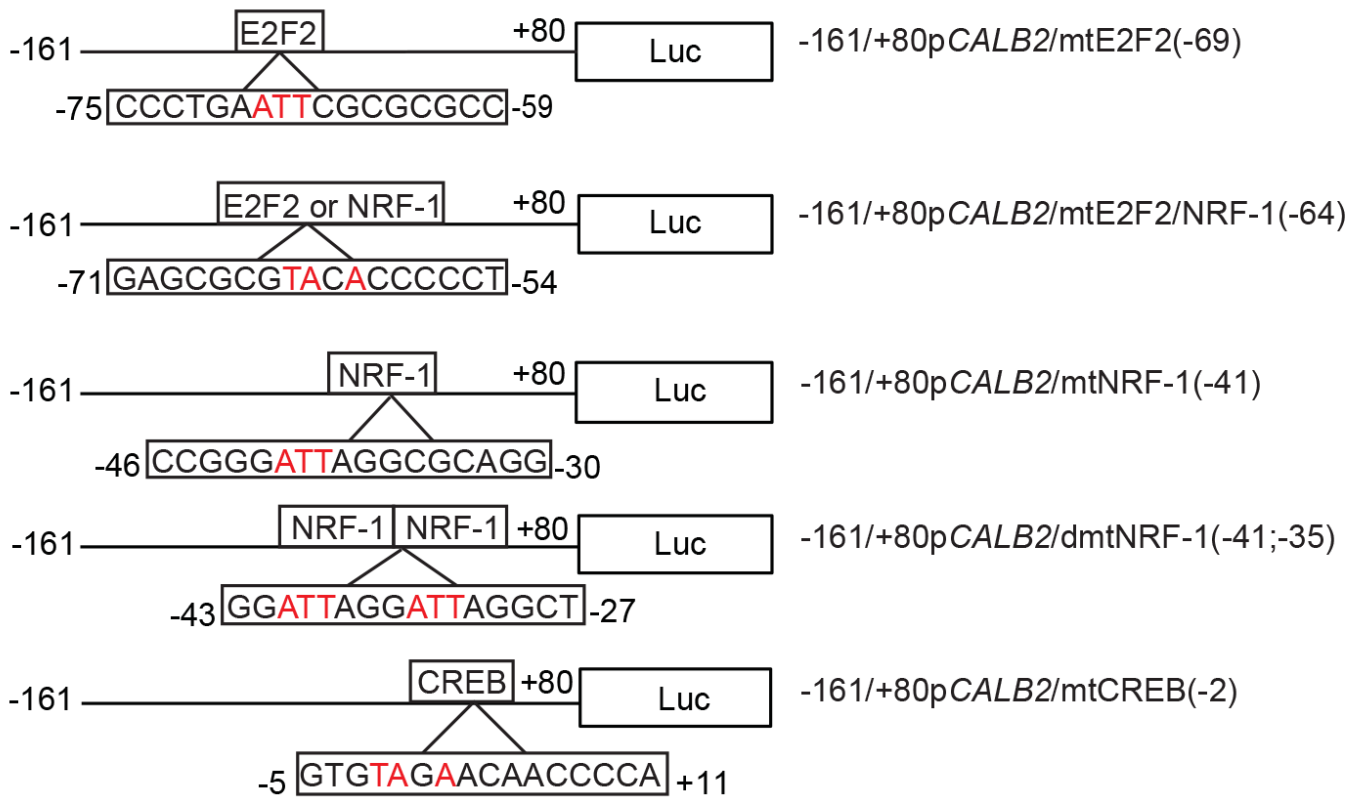

C

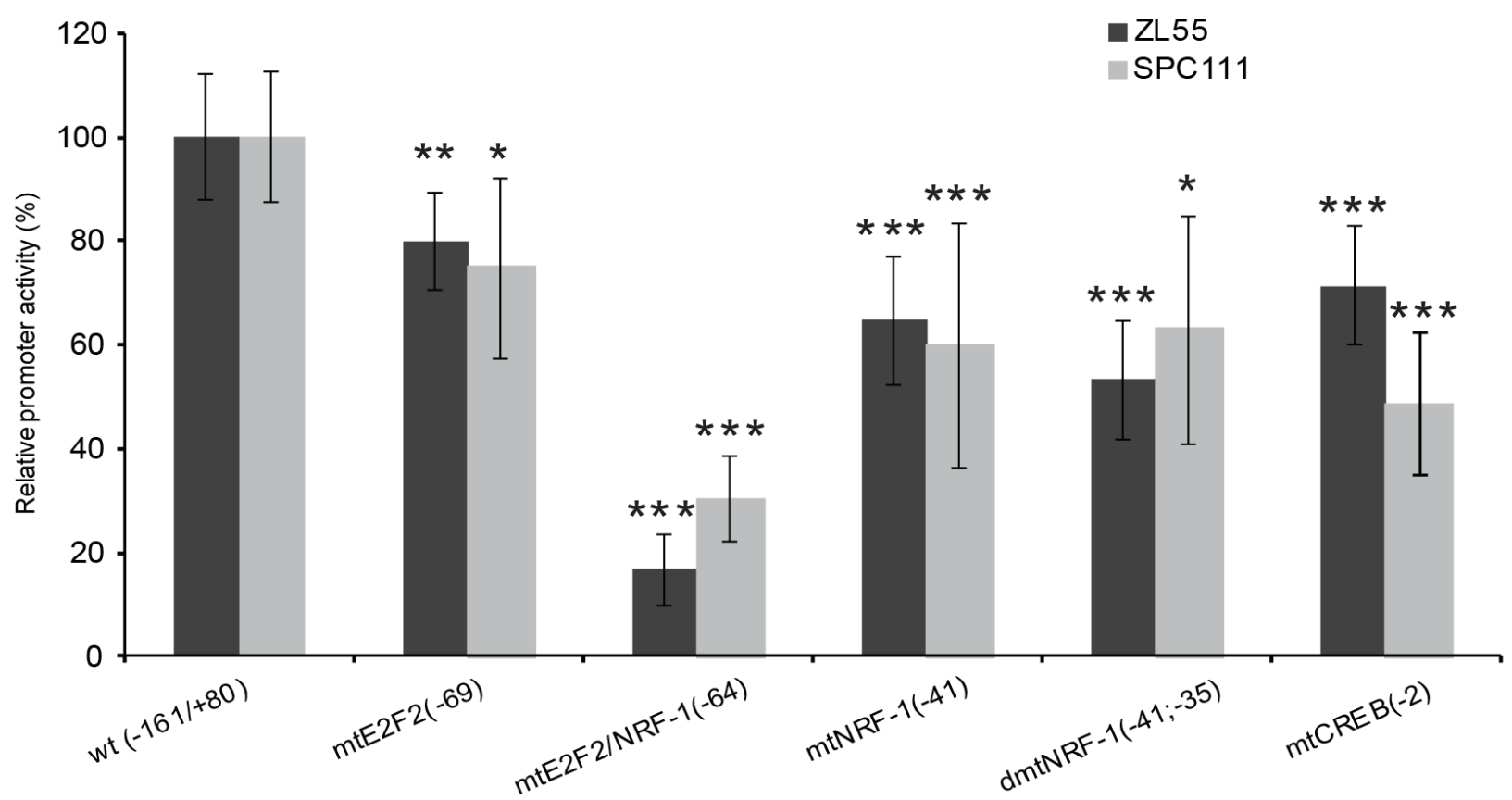

Figure 4: Effect of site-directed mutagenesis of transcription factor binding sites on the $-161 /+80 \mathrm{bp} C A L B 2$ promoter activity. (A) Predicted potential TF binding sites (highly conserved nucleotides selected for site-directed mutagenesis are colored in red). (B) A series of mutant constructs harboring mutated nucleotides (in red) of predicted E2F2, NRF-1 and CREB binding sites. Numbers indicate the position of the first (from the left to the right) mutated nucleotide. (C) The wild-type reporter plasmid expression was arbitrarily set to $100 \%$ and the reporter activity of the mutants was expressed as a percentage of the wild-type construct. Mea $\pm \operatorname{SD} n=3 ;{ }^{*} p<0.05$; $* * p<0.01 ; * * * p<0.005$. 
kinetics of transient and cell cycle-dependent calretinin expression was observed by immunofluorescence (Figure 6B), suggesting that calretinin expression is cell cycle- dependent, being upregulated in G1/S phase of the cell cycle.

\section{DISCUSSION}

In the present study we found cis-regulatory sequence elements that are essential for calretinin expression in mesothelioma cells, and identified NRF-1/ E2F2 as transcription factors binding to this regulatory sequence.

A

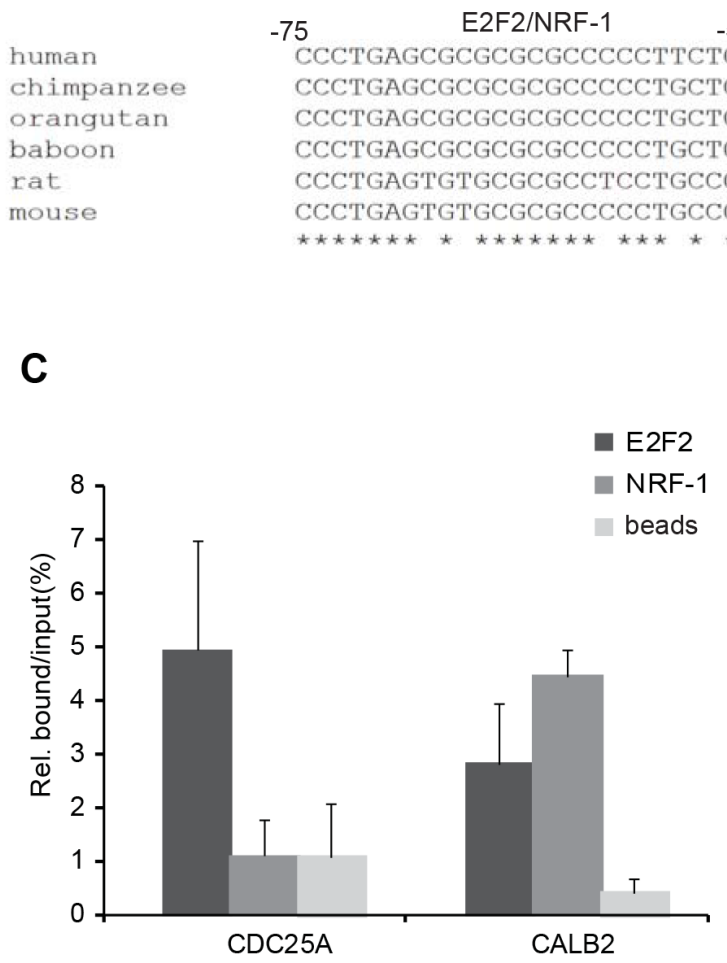

Mechanisms regulating calretinin expression have been investigated in neuronal cells and colon adenocarcinoma cells, whereas in mesothelioma cells they have not been thoroughly explored yet. A $1.5 \mathrm{~kb}$ stretch of the mouse Calb2 promoter $(-1485 /+60 \mathrm{bp})$ was demonstrated to drive reporter expression in cultured neuronal cell derived from primary embryonic mouse brain tissue [12]. Additionally, a bipartite butyrate-responsive element in the human CALB2 promoter was found to act as a repressor element upon butyrate treatment in colon carcinoma but not in mesothelioma cells [16]. However, specific cis-regulatory elements positively regulating calretinin expression had not yet been identified.

B

\begin{tabular}{|c|c|c|c|c|c|c|c|}
\hline Nuclear extract & - & + & + & + & + & + & + \\
\hline Competitor WT & - & - & $\leftarrow$ & $\square$ & - & - & - \\
\hline Competitor MT & - & - & - & - & + & - & - \\
\hline Biotin labeled & + & + & + & + & + & + & + \\
\hline Antibody & - & - & - & - & - & NRF-1 & $\mathrm{E} 2 \mathrm{~F} 2$ \\
\hline Lane & 1 & 2 & 3 & 4 & 5 & 6 & 7 \\
\hline
\end{tabular}

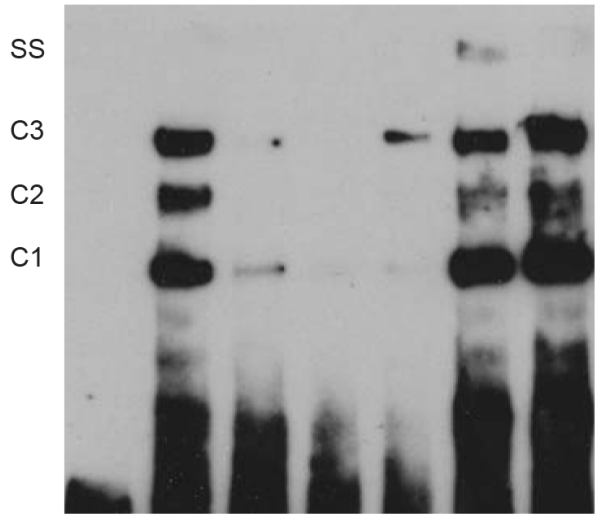

wt E2F2/NRF-1/like site CCCTGAGCGCGCGCGCCCCCTTCTG mut E2F2/NRF-1/like site CCCTGAGCGCG TACACCCCCTTCTG
D

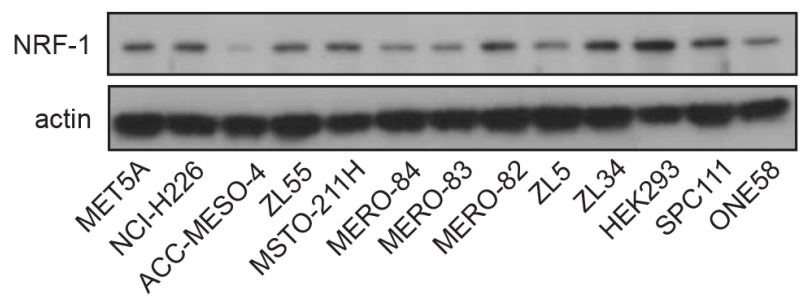

E

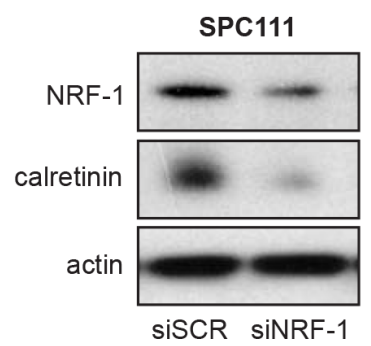

Figure 5: NRF-1 and E2F2 bind to the CALB2 promoter. (A) Nucleotide sequence comparison reveals high homology in the CALB2 promoter regions of different species in the stretch containing E2F2/NRF-1 predicted binding sites. The analysis was performed using the ClustalW2 software. Asterisks indicate conserved nucleotides. (B) EMSA assay showing that a 25bp-oligo containing E2F2/NRF1-like sites forms three DNA-protein complexes $(\mathrm{C} 1, \mathrm{C} 2, \mathrm{C} 3)$ when incubated in with the ZL55 cells-derived nuclear extracts. Addition of a NRF-1 antibody but not of one against E2F2 resulted in a supershift (SS). (C) qPCR analysis on CDC25A and CALB2 promoter regions after ChIP-experiments. Data of two independent experiments were normalized to input. (D) NRF-1 protein expression in different cell lines. Actin is used as loading control. (E) NRF-1 silencing resulted in downregulation of calretinin expression. 
Genomic sequence surrounding transcription start site of CALB2 gene contains a $\mathrm{GC}$-rich region indicating a possible role for DNA methylation in regulating calretinin expression. However, 5-Aza-CdR, a DNA hypomethylating agent, did not increase calretinin expression in low-calretinin expressing SPC111 cells. It even resulted in a decrease in calretinin expression levels indicating that a certain degree of methylation is required for optimal/maximal CALB2 transcription. Additionally, we did not observe differential methylation status of $C A L B 2$ promoter between epithelioid and biphasic mesothelioma in tumors from TCGA database or a strong negative correlation of promoter methylation with gene expression. Thus altered DNA methylation of the CALB2 promoter is very likely not responsible for the differences in calretinin expression levels between low-expressing biphasic/sarcomatoid and high-expressing epithelioid mesothelioma cells.
We further characterized a stretch of $1 \mathrm{~kb}$ $(-835 /+80 \mathrm{bp})$ of the human CALB2 promoter by creating four different 5 '-deletion promoter reporter constructs and testing their activity in four different mesothelioma cell lines. The $-161 /+80 b p$ fragment of the $C A L B 2$ promoter was identified as the minimal element resulting in sustained transcriptional activity in all tested mesothelioma cell lines. This is consistent with the previously defined minimal mouse Calb2 promoter $(-115 /+54 b p)$ shown to be active in rat cortical neuronal cells, rat cerebellar granule cells, colon adenocarcinoma (WiDr) and mesothelioma cells (SPC111) [13, 14]. Moreover, we found that the transcriptional activity of the $-161 /+80$ bp $C A L B 2$ promoter reporter was highly correlated with $C A L B 2$ expression levels. We are aware that using as normalizer pRL-TK plasmid, which carries the Renilla luciferase gene under the HSV-1 TK promoter might theoretically be affected by different levels of

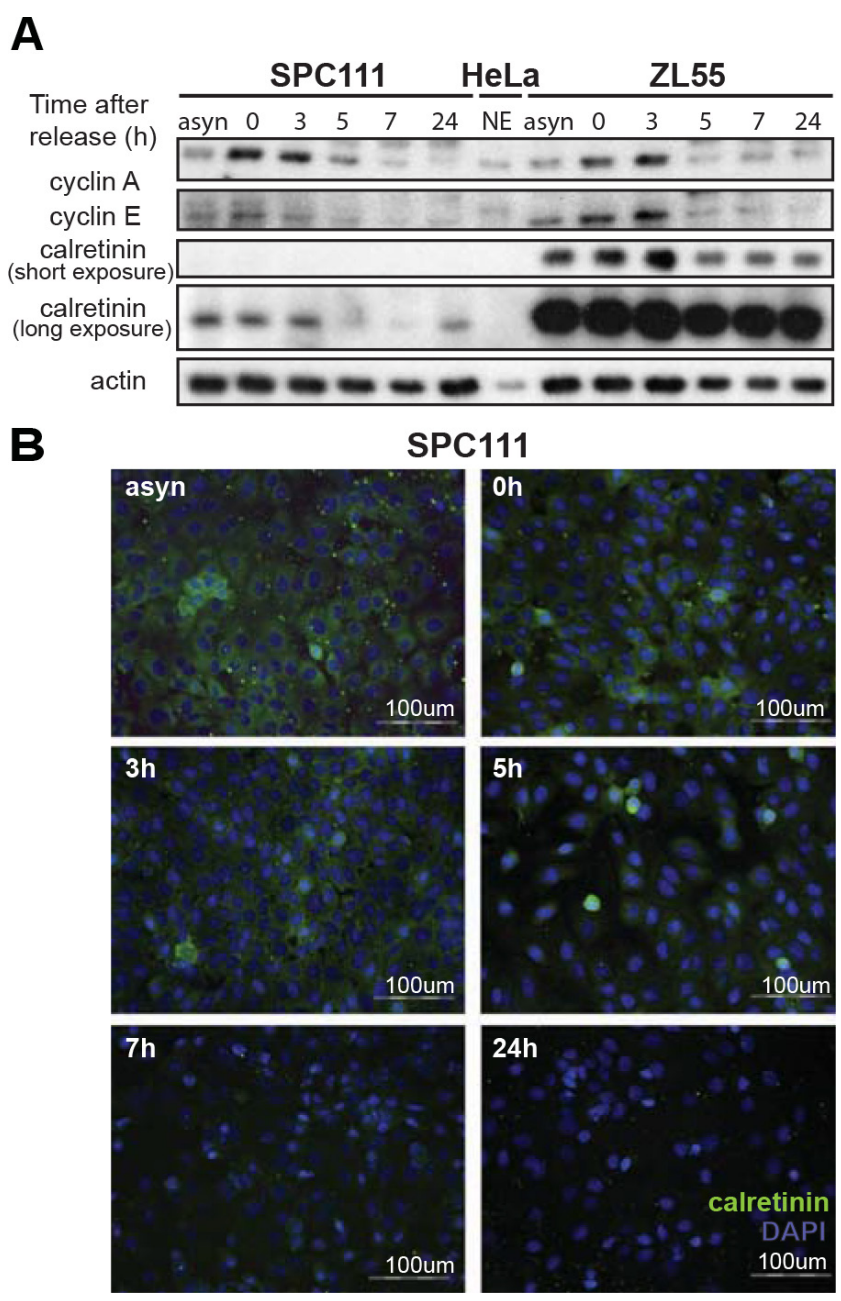

Figure 6: Cell cycle-dependent regulation of calretinin expression. (A) Calretinin levels in protein lysates from ZL55 and SPC111 synchronized cells collected at different time points $(0 \mathrm{~h}, 3 \mathrm{~h}, 5 \mathrm{~h}, 7 \mathrm{~h}, 24 \mathrm{~h})$ after removal of thymidine block. Analysis of cyclin A and cyclin E expression was used as a reference for cell cycle progression. A nuclear extract of HeLa cells is used to identify the position of the bands of cyclin A and cyclin E Due to the considerably different calretinin expression levels of ZL55 and SPC111 cells, two different exposure times are presented. (B) Immunofluorescence analysis of SPC111 cells using calretinin antibody (green) at the same time points as in (A) Cells nuclei are stained with DAPI (blue), and calretinin immunofluorescence is shown in green. 
Specificity protein 1 (Sp1) [31]. Rao et al reported recently overexpression of $\mathrm{Sp} 1$ in mesothelioma compared to normal mesothelium [32]. However, the variation of Sp1 levels between the lowest and the highest expressing mesothelioma cell line investigated was 4-fold. Since we observed an about 30 -fold difference in CALB2 promoter activity between the different mesothelioma cell lines, we can reasonably assume that the difference is not due to differential expression of the normalizer.

In silico analysis of the human $-161 /+80 \mathrm{bp}$ CALB2 minimal promoter region revealed a series of potential functional transcription factors (TF) among which NRF-1, E2F2 and CREB were of greatest interest for the following reasons. NRF-1 is a transcription factor implicated in mitochondrial biogenesis and function [33] and was predicted as TF binding to the $C A L B 2$ promoter [34]. Computer-assisted identification predicted CALB2 to be an E2F target gene as well [35]. Finally, CREB had been demonstrated as an asbestos activated TF in human mesothelial cells [26]. Mutation of E2F2 (-69), NRF-1 (-41), two NRF-1 (-41;-35) and CREB (-2) predicted binding sites significantly reduced CALB2 promoter activity in ZL55 and SPC111 cells. Mutations in the E2F2/NRF-1 $(-64 ;-63 ;-61)$ putative binding sites (GAGCGCG $\underline{\mathbf{C}} \mathbf{C} \underline{\mathbf{G} C C C C T}$; bold indicates NRF-1 consensus, underlined are the nucleotides mutated in the functional assay) led to a $70-80 \%$ decrease in the promoter activity revealing this sequence as the most important cisacting site. In the studies of Billing-Marczak et al [13, 14], an essential element for the promoter activity in the mouse Calb2 promoter $(-115 /+54 \mathrm{bp})$ was located at the $-91 /-$ 80bp position and identified as an "AP-2 like" sequence (CGECCCCTTCCG, in bold are nucleotides overlapping with NRF-1 consensus, underlined are the nucleotides that had been mutated in the functional assay). Although transacting factors were not identified, functional inactivation in neuronal cells was obtained by mutating one nucleotide also present in the E2F2/NRF-1 putative binding site. The same mutation did not abolish promoter activity in cancer cells [14]. This could be interpreted in two ways: either mutating a single base in the E2F2/NRF-1 binding site is not enough to abolish activity in cancer cells or different transcription factors are operational in neuronal and cancer cells.

A nucleotide sequence analysis revealed that the E2F2/NRF-1-site in the CALB2 promoter region displays a high degree of identity across different species. An EMSA assay revealed three different DNA-protein complexes and chromatin immunoprecipitation assay showed the presence of both NRF-1 and E2F2 bound to CALB2 promoter. This is consistent with a previous study demonstrating that NRF-1 is a co-regulator of E2F family members target genes [27]. For all these reasons and since we observed similar expression of NRF-1 in a panel of mesothelioma cell lines with different calretinin expression levels, it is most likely that NRF-1 is a part of a protein complex that altogether activates calretinin expression. Identified proteins interacting with NRF-1 include SP4 (specificity protein 4) [36]. Interestingly, the in silico analysis on $-160 /+80$ bp CALB2 promoter region predicted a SP4 binding site located next to the E2F2/NRF-1 site. SP4 expression is tissue specific, primarily expressed in the brain, some epithelial tissues, testis and developing teeth [37] and its coordinate activity with NRF-1 has been described to couple energy generation and neuronal activity [38]. Further studies should investigate whether SP4 is involved in the regulation of calretinin expression.

E2F factors are known to regulate S-phase entry [39]. Consistent with E2F regulating CALB2 promoter activity, calretinin expression was found to be cell cycle-dependent with a maximum level of expression at G1, and progressively decreased during cell cycle progression. Since calretinin expression is associated with better clinical outcome [7-9], it would be interesting to investigate whether tumor cells positive for calretinin are growth arrested cells.

Knowledge about mechanisms regulating NRF-1 and E2F would help for a better understanding of the complex biology of mesothelioma, where loss of calretinin expression during epithelioid tumor progression is associated with worst outcome (Vrugt et al, ms in preparation).

Investigation of the promoter of another MPM marker, mesothelin, has led to the discovery of a cancerspecific element driving mesothelin overexpression in cancers [40]. In the transgenic MexTAg mouse model, where the mesothelin promoter is placed upstream of the large $\mathrm{T}$ antigen, the promoter becomes active in mesothelial cells after asbestos exposure, leading to asbestos induced mesothelioma [41]. This suggests that different transcription factors act on the mesothelin promoter in normal cells and cancer cells. In several studies aiming at driving suicide gene expression in cancer cells, a $2.2 \mathrm{~kb}$ human $C A L B 2$ promoter fragment was reported not to be specific for cancer cells [42, 43]. In our study, we describe a $C A L B 2$ promoter fragment $(-161 /+80$ bp $)$ with activity proportional to calretinin expression and identified NRF-1/E2F2 as specific transactivating factors. Future studies will assess whether this promoter activity is differently regulated in cancer and neuronal cells.

Although this work cannot directly exclude a role of post-transcriptional mechanisms such as RNA stability in regulating calretinin expression in mesothelioma cells, this is the first study defining trans-activating factors in a gene that is not only a diagnostic and prognostic marker, but also has a functional role in MPM. Our experiments demonstrate that calretinin expression is activated at the transcriptional level by NRF-1 and E2F2 transcription factors and that expression levels are cell cycle-dependent. Given recent findings about E2Fs involvement in processes such as regulation of cell fate, occasionally linked to 
metabolic adaptation [44], our results on the regulation of calretinin expression are expected to have a persistent impact for the understanding of MPM development.

\section{MATERIALS AND METHODS}

\section{Cell culture}

The following mesothelioma cell lines have been used: ZL55, ZL5, ZL34 and SPC111 from our laboratory [45]; NCI-H226, MSTO-211H, MeT5A [46] were obtained from ATCC; ACC-MESO-4 [47] were obtained from Riken BRC; and MERO-82, MERO-83, MERO-84 [48] and ONE58 [49] were obtained from the European Collection of Cell Cultures. MPM cells established in our laboratory were maintained as described by Thurneysen et al [50] and were authenticated by DNA fingerprinting of short tandem repeat loci (Microsynth, Switzerland). The other cell lines were cultured in D-MEM-F12 supplemented with 15\% FCS and 1\% Penicillin/ Streptomycin solution. HEK293 cells were cultured in DMEM high glucose medium supplemented with $10 \%$ FCS and $1 \%$ penicillin/streptomycin. All cells were cultured at $37^{\circ} \mathrm{C}$ in a humidified $5 \% \mathrm{CO}_{2}$ atmosphere.

\section{Gene expression analysis}

RNA extraction using Qiagen RNAeasy ${ }^{\circledR}$ and cDNAs was prepared from 400-500 ng of total RNA (Qiagen QuantiTect ${ }^{\circledR}$ Reverse Transcription protocol) [51]. Selected gene expression analysis using MIQE [52] compliant protocols was conducted as previously described [51]. Briefly, cDNA was amplified by the SYBR-Green PCR assay and products were detected on a 7900HT Fast real-Time PCR system (SDS, ABI/Perkin Elmer). Relative mRNA levels were determined by comparing the PCR cycle thresholds between cDNA of a specific gene and histone ( $\Delta \mathrm{Ct}$ method). The following primers were used: calretinin (5'-GCGAACCGGCCGTACGATGA-3' and 5'-AGAGGCCCAATTTGCCATCCCCG-3), Mage-C1 (5'-GGGATGTGCTGAGTGGAATAG-3' and 5'-CTCCC GGTACTCTAGGTAATGT-3'), CTAG1B (NY-ESO-1) (5'-GTCCGGCAACATACTGACTATC-3' and 5'-GTGA TCCACATCAACAGGGAA-3').

\section{Western blot analysis}

Total protein extracts were prepared by lysing the cells with hot Laemmli sample buffer $(60 \mathrm{mM}$ Tris$\mathrm{Cl} \mathrm{pH}$ 6.8, $100 \mathrm{mM}$ DTT, 5\% glycerol, 1, 7\% SDS) and pressed few times through syringes (26 G). Protein concentration was determined using a Pierce ${ }^{\mathrm{TM}} 660 \mathrm{~nm}$ Protein Assay (Thermo Scientific). A total of $5 \mu \mathrm{g}$ protein per extract was separated on denaturing 10-20\% gradient SDS-PAGE gels. Proteins were transferred on PVDF transfer membranes $(0.45 \mu \mathrm{m}$, Perkin Elmer $)$.
For Western blotting, membranes were probed with the following primary antibodies: anti-calretinin (Sigma, HPA007306), anti-cyclin E (Santa Cruz Sc-247), anticyclin A (Millipore, 06-138), anti-NRF-1 (Santa Cruz SC33771, H300) and mouse anti-actin (\#69100) from MP Biomedicals. Membranes were then incubated with the secondary antibody rabbit anti-mouse IgG-HRP (A-5420) from Antell, and goat anti-rabbit IgG-HRP (\#7074) from Cell Signaling. The signals were detected by enhanced chemiluminescence $\left(\mathrm{ECL}^{\mathrm{TM}}\right.$ Western Blotting Reagents, GE Healthcare) and detected on photosensitive film (Super RX Fuji x-Ray Film, Fujifilm). Relative quantification was assessed using ImageJ (NIH).

\section{5-aza-2'deoxycytidine treatment of cells}

On the first day, $2.5 \times 10^{4}$ cells were seeded in a 6-well plate and on the next day the medium was replaced with the medium containing $100 \mathrm{nM}$ and $250 \mathrm{nM}$ of 5-Aza-2-CdR. After $24 \mathrm{~h}$, the drug containing medium was replaced with the fresh medium. On the fifth day, cells were treated again with 5-Aza-2CdR for $24 \mathrm{~h}$ and then the medium was replaced by fresh one. Cells were kept in culture for another $24 \mathrm{~h}$ after which samples were collected for RT-PCR and Western blot analysis.

\section{In silico analysis}

Analysis of the $241 \mathrm{bp}$ of the promoter sequence for potential functional transcription factors was carried out using MatInspector software (Genomatix Software GmbH, Munich, Germany) [25].

Level 3 normalized DNA methylation data and clinical information was downloaded from The Cancer Genome Atlas (TCGA) data portal on August 10th, 2015. Normalized CALB2 gene expression values (RNAseq) from the same TCGA samples were downloaded from the UCSC cancer genome browser on August 10th, 2015. There were 87 mesotheliomas with available Illumina HumanMethylation450 methylation, gene expression, and clinical data. The majority of tumors were epithelioid histology ( $n=57)$, with $n=23$ biphasic, $n=5$ diffuse not otherwise specified and $n=2$ sarcomatoid tumors. Patient demographic and tumor characteristics are provided in Supplementary Table 1.

\section{Plasmids constructs and side-directed mutagenesis}

To investigate the control of CALB2 transcription, $838 \mathrm{bp}, 419 \mathrm{bp}, 216 \mathrm{bp}$ and $161 \mathrm{bp}$ upstream and $80 \mathrm{bp}$ downstream of the CALB2 transcription starting site were amplified from genomic DNA ZL55 cells

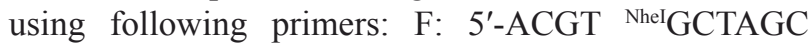
${ }^{-838}$ ACATTCCCACGATGTCCCTA-3' (Addgene, 66750); F: 5'- ACGT $^{\text {Nhel }}$ GCTAGC $^{-419}$ AGCTCTTCCTGCTGTGGA 
AGGATCAGAA-3' (Addgene, 66747); F: 5'-ACGT ${ }^{\text {NheI } G C}$ TAGC ${ }^{-264}$ AAGTGGTGGATGTACTCAAG-3' (Addgene, 66746); F:5'- ACGT HindIII AAGCTT ${ }^{-161}$ TCTCAGCGCA GAGGTAAGGG-3' (Addgene 66745)- along with the

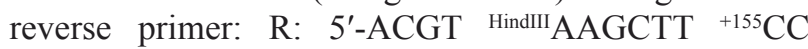
ATATTTCCAGGAACTGGGACGCCGTC-3'. In order to avoid ORF shifts due to the start codon of $C A L B 2$ gene but still to include the 5'-UTR, NcoI restriction sites in 3' site of the PCR product along with the restriction site within the forward primer $\left(5^{\prime}\right)$ were used to subclone amplicons into the pGL3-basic vector. To obtain constructs with specific mutations, the QuikChange II Site-Directed Mutagenesis kit (Stratagene) was used (mtE2F (-69)-, Addgene 66743; mtCREB (-2), Addgene 66751; mtNRF-1 (-41), Addgene 66744, dmtNRF-1 (-41;-35)-, Addgene 66741, E2F2/NRF-1 (-64), Addgene 66742).

\section{Transient transfections and reporter assays}

To investigate CALB2 transcription, the dual luciferase assay was used. Briefly, the different constructs were transfected together with Renilla Luciferase (50:1) in cells seeded in 12 wells (100'000 cells/well) as previously described [53]. After 48 h, cells were lysed and analyzed using Dual-Luciferase reporter assay system according to manufacturer's instruction (Promega, Madison, Wi, USA).

\section{Electrophoretic mobility shift assay (EMSA)}

Nuclear extracts were prepared using the NE-PER Nuclear and Cytoplasmic Extraction Reagent (Pierce) following the manufacturer's protocol. The binding reaction was performed by incubating $5 \mu \mathrm{g}$ of nuclear extract with $125 \mathrm{fmol}$ biotin labelled oligonucleotide (5'-CCCTGAGCGCGCGCGCCCCCTTCTG-3') in the presence of 10mM Tis- $\mathrm{HCl} \mathrm{pH} 8.0,25 \mathrm{mM} \mathrm{NaCl}, 10 \mathrm{mM}$ DTT, 5\% glycerol, $10 \mathrm{mM} \mathrm{MgCl}, 2 \mu \mathrm{M} \mathrm{ZnCl}, 1 \mu \mathrm{g}$ salmon sperm dsDNA, $1 \% \mathrm{NP}-40$ and incubated on ice for $50 \mathrm{~min}$. For competition reactions, the nuclear extracts were incubated with the specific unlabelled oligonucleotides for $10 \mathrm{~min}$ prior to addition of biotin-labelled oligonucleotides and incubated $40 \mathrm{~min}$ on ice. For the supershift experiments, specific antibodies (NRF-1 ab34682 and E2F2 sc699 $\times$ ) were added after 30 min incubation of the nuclear extracts and biotin-labeled probes and incubated another $20 \mathrm{~min}$ on ice. The samples were separated on a $6 \% 0.5 \times \mathrm{TBE}$ gel, transferred on a nylon membrane and visualized using the Chemiluminescent Nucleic Acid Detection Module (89880) according to the manufacturer's protocol.

\section{Chromatin immunoprecipitation (ChIP)}

ChIP was carried out according to the protocol previously described [54]. In brief, cultured cells $\left(4 \times 10^{6}\right)$ were treated with $1 \%$ formaldehyde to crosslink proteins to DNA. Chromatin was sonicated using a Bioruptor ultrasonic cell disruptor (Diagenode) to shear genomic DNA to fragments between $100 \mathrm{bp}$ and 200bp. Chromatin $(20 \mu \mathrm{g})$ was diluted tenfold with immunoprecipitation buffer (16.7 mM Tris-HCl (pH 8.1), $167 \mathrm{mM} \mathrm{NaCl}$, $1.2 \mathrm{mM}$ EDTA, $0.01 \% \mathrm{SDS}$ and $1.1 \%$ Triton X-100) and then immunoprecipitated overnight with the corresponding antibodies (NRF-1 Abcam ab34682 and E2F2 Santa Cruz sc699X). After washing, elution and de-crosslinking, the precipitated DNA was purified with phenol-chloroform, ethanol precipitated and quantified by quantitative PCR. Following primers were used: CDC25A (5'-TTTCGCGGTAATAGCGGCTC-3' and 5'-TAGCTGCCATTCGGTTGAGAG-3') and CALB2 (5'-AGGTAAGGGCCCTCTAGGAGT-3' and 5'-CTGCCC TTATATACGCTCTGGA-3').

\section{RNA interference by siRNA}

For the down-regulation of NRF-1 with small interfering RNAs (siRNA), SPC111 cells were transfected with $25 \mathrm{nM}$ Qiagen smartpool or individual siRNAs targeting NRF-1 or control non targeting (NT) siRNA (Thermo Scientific Dharmacon), according to the manufacturer's reverse transfection protocol as previously described [53]. $3 \times 10^{4}$ cells were then plated in and whole cell lysate was prepared after $72 \mathrm{~h}$.

\section{Cell synchronization}

Cells were synchronized at the G1/S and G2/M border using a thymidine double-block/nocodazole release protocol [55]. Briefly, cells were seeded in 6-well $\left(5 \times 10^{4}\right.$ cells/well $)$ then $24 \mathrm{~h}$ later were treated with $2 \mathrm{mM}$ thymidine for $12 \mathrm{~h}$ and released for $12 \mathrm{~h}$ in fresh medium before the second block was performed for another $12 \mathrm{~h}$ with $2 \mathrm{mM}$ thymidine. Cells were then washed three times in phosphate buffer saline (PBS) and either collected (hours after treatment $=0$ ) or released in fresh medium containing $40 \mathrm{ng} / \mathrm{ml}$ nocodazole to induce mitotic arrest (G2/M) for different time periods.

\section{Immunofluorescence}

SPC111 cells were grown on 12-mm glass coverslips in 24-well plates. Using the same synchronization protocol described above, asynchronized and synchronized cells were fixed for 10 min with $4 \%$ paraformaldehyde and permeabilized with $0.05 \%$ saponin for $5 \mathrm{~min}$. The cells were then incubated over night at $4 \mathrm{C}$ with an anti-calretinin antibody diluted in PBS containing 1\% bovine serum albumin. Secondary antibodies, Alexa Fluor 488- conjugated goat anti-rabbit IgG (Life Technologies) antibody was added for $1 \mathrm{~h}$ at RT. Nuclear DNA was stained using DAPI. Coverslips were mounted using Prolong Gold antifade reagent (Life Technologies). Images 
were acquired using an Olympus $B \times 61$ microscope (Schwerzenbach, Switzerland) equipped with an F-view camera for conventional fluorescence imaging. The image capture was controlled with the AnalySISPro software (Soft Imaging System, Münster, Germany).

\section{Statistics}

Data are expressed as mean \pm standard deviation of multiple experiments. Statistical analysis was performed using Mann-Whitney tests using StatView 5.0.1 (SAS institute). Spearman's correlation tests were used to compare TCGA promoter methylation versus gene expression levels. Differences were considered statistically significant at $p<0.05$.

\section{ACKNOWLEDGMENTS}

The authors are grateful to the members of Laboratory of Molecular Oncology for helpful discussion.

\section{GRANT SUPPORT}

This work was supported by the Swiss National Science Foundation Sinergia grant CRSII3 147697/1 (to EFB and BS), P20GM104416 (to BC) and the Stiftung für Angewandte Krebsforchung (to EFB, RS and WW).

\section{CONFLICTS OF INTEREST}

The authors declare no conflicts of interest.

\section{REFERENCES}

1. Tsao AS, Wistuba I, Roth JA, Kindler HL. Malignant pleural mesothelioma. J Clin Oncol. 2009; 27:2081-2090.

2. Roe OD, Stella GM. Malignant pleural mesothelioma: history, controversy and future of a manmade epidemic. European respiratory review. 2015; 24:115-131.

3. Kawasaki H, Kretsinger RH. Calcium-binding proteins 1: EF-hands. Protein profile. 1995; 2:297-490.

4. Doglioni C, Tos APD, Laurino L, Iuzzolino P, Chiarelli C, Celio MR, Viale G. Calretinin: A novel immunocytochemical marker for mesothelioma. Am J Surgical Pathol. 1996; 20:1037-1046.

5. Ordonez NG. Value of calretinin immunostaining in diagnostic pathology: a review and update. Appl Immunohistochem Mol Morphol. 2014; 22:401-415.

6. Kim JH, Kim GE, Choi YD, Lee JS, Lee JH, Nam JH, Choi C. Immunocytochemical panel for distinguishing between adenocarcinomas and reactive mesothelial cells in effusion cell blocks. Diagn Cytopathol. 2009; 37:258-261.

7. Otterstrom C, Soltermann A, Opitz I, Felley-Bosco E, Weder W, Stahel RA, Triponez F, Robert JH, Serre-Beinier V. CD74: a new prognostic factor for patients with malignant pleural mesothelioma. Br J Cancer. 2014; 110:2040-2046.

8. Kao SC, Klebe S, Henderson DW, Reid G, Chatfield M, Armstrong NJ, Yan TD, Vardy J, Clarke S, van Zandwijk N, McCaughan B. Low calretinin expression and high neutrophil-to-lymphocyte ratio are poor prognostic factors in patients with malignant mesothelioma undergoing extrapleural pneumonectomy. J Thorac Oncol. 2011; 6:1923-1929.

9. Linton A, Pavlakis N, O'Connell R, Soeberg M, Kao S, Clarke S, Vardy J, van Zandwijk N. Factors associated with survival in a large series of patients with malignant pleural mesothelioma in New South Wales. Br J Cancer. 2014; 111:1860-1869.

10. Blum W, Schwaller B. Calretinin is essential for mesothelioma cell growth/survival in vitro: a potential new target for malignant mesothelioma therapy? Int J Cancer. 2013; 133:2077-2088.

11. Camp AJ, Wijesinghe R. Calretinin: modulator of neuronal excitability. Int J Biochem Cell Biol. 2009; 41:2118-2121.

12. Strauss KI, Kuznicki J, Winsky L, Kawagoe JI, Hammer M, Jacobowitz DM. The mouse calretinin gene promoter region: structural and functional components. Brain research Molecular brain research. 1997; 49:175-187.

13. Billing-Marczak K, Buzanska L, Winsky L, Nowotny M, Rudka T, Isaacs K, Belin MF, Kuznicki J. AP2-like cis element is required for calretinin gene promoter activity in cells of neuronal phenotype differentiated from multipotent human cell line DEV. Biochimica et biophysica acta. 2002; 1577:412-420.

14. Billing-Marczak K, Zieminska E, Lesniak W, Lazarewicz JW, Kuznicki J. Calretinin gene promoter activity is differently regulated in neurons and cancer cells. Role of AP2-like cis element and zinc ions. Biochimica et biophysica acta. 2004; 1678:14-21.

15. Marilley D, Vonlanthen S, Gioria A, Schwaller B. Calretinin and calretinin-22k increase resistance towards sodium butyrate-induced differentiation in CaCo-2 colon adenocarcinoma cells. Exp Cell Res. 2001; 268:93-103.

16. Haner K, Henzi T, Pfefferli M, Kunzli E, Salicio V, Schwaller B. A bipartite butyrate-responsive element in the human calretinin (CALB2) promoter acts as a repressor in colon carcinoma cells but not in mesothelioma cells. J Cell Biochem. 2010; 109:519-531.

17. Graham FL, Smiley J, Russell WC, Nairn R. Characteristics of a human cell line transformed by DNA from human adenovirus type 5. J Gen Virol. 1977; 36:59-74.

18. Cai H, Kumar N, Baudis M. arrayMap: a reference resource for genomic copy number imbalances in human malignancies. PLoS One. 2012; 7:e36944.

19. Krismann M, Muller KM, Jaworska M, Johnen G. Severe chromosomal aberrations in pleural mesotheliomas with unusual mesodermal features. Comparative genomic hybridization evidence for a mesothelioma subgroup. J Mol Diagn. 2000; 2:209-216. 
20. Destro A, Ceresoli GL, Baryshnikova E, Garassino I, Zucali PA, De Vincenzo F, Bianchi P, Morenghi E, Testori A, Alloisio M, Santoro A, Roncalli M. Gene methylation in pleural mesothelioma: Correlations with clinico-pathological features and patient's follow-up. Lung Cancer. 2007; 59:369-376.

21. Ren B, Cam H, Takahashi Y, Volkert T, Terragni J, Young RA, Dynlacht BD. E2F integrates cell cycle progression with DNA repair, replication, and G/M checkpoints. Genes Dev. 2002; 16:245-256.

22. Gardiner-Garden M, Frommer M. CpG islands in vertebrate genomes. J Mol Biol. 1987; 196:261-282.

23. Li E, Zhang Y. DNA methylation in mammals. Cold Spring Harb Perspect Biol. 2014; 6:a019133.

24. Sigalotti L, Coral S, Altomonte M, Natali L, Gaudino G, Cacciotti P, Libener R, Colizzi F, Vianale G, Martini F, Tognon M, Jungbluth A, Cebon J, et al. Cancer testis antigens expression in mesothelioma: role of DNA methylation and bioimmunotherapeutic implications. Br J Cancer. 2002; 86:979-982.

25. Quandt K, Frech K, Karas H, Wingender E, Werner T. MatInd and MatInspector: new fast and versatile tools for detection of consensus matches in nucleotide sequence data. Nucleic acids research. 1995; 23:4878-4884.

26. Shukla A, Bosenberg MW, Macpherson MB, Butnor KJ, Heintz NH, Pass HI, Carbone M, Testa JR, Mossman BT. Activated cAMP Response Element Binding Protein Is Overexpressed in Human Mesotheliomas and Inhibits Apoptosis. Am J Pathol. 2009; 175:2197-2206.

27. Cam H, Balciunaite E, Blais A, Spektor A, Scarpulla RC, Young R, Kluger Y, Dynlacht BD. A common set of gene regulatory networks links metabolism and growth inhibition. Molecular cell. 2004; 16:399-411.

28. Hateboer G, Wobst A, Petersen BO, Le Cam L, Vigo E, Sardet C, Helin K. Cell cycle-regulated expression of mammalian CDC6 is dependent on E2F. Mol Cell Biol. 1998; 18:6679-6697.

29. Dulic V, Lees E, Reed SI. Association of human cyclin E with a periodic G1-S phase protein kinase. Science. 1992; 257:1958-1961.

30. Pagano M, Pepperkok R, Verde F, Ansorge W, Draetta G. Cyclin $\mathrm{A}$ is required at two points in the human cell cycle. The EMBO journal. 1992; 11:961-971.

31. Shifera AS, Hardin JA. Factors modulating expression of Renilla luciferase from control plasmids used in luciferase reporter gene assays. Analytical biochemistry. 2010; 396:167-172.

32. Rao M,Atay S, Shukla V, Hong Y, Upham T, Ripley T, Hong JA, Zhang M, Reardon E, Fetsch P, Miettinen M, Li X, Peer CJ, et al. Mithramycin Depletes Specificity Protein 1 and Activates p53 to Mediate Senescence and Apoptosis of Malignant Pleural Mesothelioma Cells. Clin Cancer Res. 2015.
33. Kelly DP, Scarpulla RC. Transcriptional regulatory circuits controlling mitochondrial biogenesis and function. Genes Dev. 2004; 18:357-368.

34. Virbasius CA, Virbasius JV, Scarpulla RC. NRF-1, an activator involved in nuclear-mitochondrial interactions, utilizes a new DNA-binding domain conserved in a family of developmental regulators. Genes Dev. 1993; 7:2431-2445.

35. Kel AE, Kel-Margoulis OV, Farnham PJ, Bartley SM, Wingender E, Zhang MQ. Computer-assisted identification of cell cycle-related genes: new targets for E2F transcription factors. J Mol Biol. 2001; 309:99-120.

36. Rual JF, Venkatesan K, Hao T, Hirozane-Kishikawa T, Dricot A, Li N, Berriz GF, Gibbons FD, Dreze M, AyiviGuedehoussou N, Klitgord N, Simon C, Boxem M, et al. Towards a proteome-scale map of the human protein-protein interaction network. Nature. 2005; 437:1173-1178.

37. Suske G. The Sp-family of transcription factors. Gene. 1999; 238:291-300.

38. Johar K, Priya A, Wong-Riley MT. Regulation of Na $(+) / K(+)$-ATPase by neuron-specific transcription factor Sp4: implication in the tight coupling of energy production, neuronal activity and energy consumption in neurons. Eur $\mathrm{J}$ Neurosci. 2014; 39:566-578.

39. Dimova DK, Dyson NJ. The E2F transcriptional network: old acquaintances with new faces. Oncogene. 2005; 24:2810-2826.

40. Hucl T, Brody JR, Gallmeier E, Iacobuzio-Donahue CA, Farrance IK, Kern SE. High cancer-specific expression of mesothelin (MSLN) is attributable to an upstream enhancer containing a transcription enhancer factor dependent MCAT motif. Cancer Res. 2007; 67:9055-9065.

41. Robinson C, van Bruggen I, SegalA, Dunham M, SherwoodA, Koentgen F, Robinson BW, Lake RA. A novel SV40 TAg transgenic model of asbestos-induced mesothelioma: malignant transformation is dose dependent. Cancer Res. 2006; 66:10786-10794.

42. Fukazawa T, Matsuoka J, Naomoto Y, Maeda Y, Durbin ML, Tanaka N. Malignant pleural mesothelioma-targeted CREBBP/EP300 inhibitory protein 1 promoter system for gene therapy and virotherapy. Cancer Res. 2008; 68: 7120-7129.

43. Inase N, Miyake S, Yoshizawa Y. Calretinin promoter for suicide gene expression in malignant mesothelioma. Anticancer Res. 2001; 21:1111-1114.

44. Julian LM, Blais A. Transcriptional control of stem cell fate by E2Fs and pocket proteins. Front Genet. 2015; 6:161.

45. Schmitter D, Lauber B, Fagg B, Stahel RA. Hematopoietic growth factors secreted by seven human pleural mesothelioma cell lines: interleukin-6 production as a common feature. Int J Cancer. 1992; 51:296-301.

46. Phelps RM, Johnson BE, Ihde DC, Gazdar AF, Carbone DP, McClintock PR, Linnoila RI, Matthews MJ, Bunn PA, Jr., Carney D, Minna JD, Mulshine JL. NCI-Navy Medical 
Oncology Branch cell line data base. J Cell Biochem Suppl. 1996; 24:32-91.

47. Usami N, Fukui T, Kondo M, Taniguchi T, Yokoyama T, Mori S, Yokoi K, Horio Y, Shimokata K, Sekido Y, Hida T. Establishment and characterization of four malignant pleural mesothelioma cell lines from Japanese patients. Cancer Sci. 2006; 97:387-394.

48. Versnel MA. . Mesothelioma. In: Masters JR, Palson, B., ed. Human cell culture. (The Netherlands: Springer), pp. 87-106.

49. Manning LS, Whitaker D, Murch AR, Garlepp MJ, Davis MR, Musk AW, Robinson BW. Establishment and characterization of five human malignant mesothelioma cell lines derived from pleural effusions. Int J Cancer. 1991; 47:285-290.

50. Thurneysen C, Opitz I, Kurtz S, Weder W, Stahel RA, Felley-Bosco E. Functional inactivation of NF2/merlin in human mesothelioma. Lung Cancer. 2009; 64:140-147.

51. Sidi R, Pasello G, Opitz I, Soltermann A, Tutic M, Rehrauer H, Weder W, Stahel RA, Felley-Bosco E. Induction of senescence markers after neo-adjuvant chemotherapy of malignant pleural mesothelioma and association with clinical outcome: an exploratory analysis. Eur J Cancer. 2011; 47:326-332.

52. Bustin SA, Benes V, Garson JA, Hellemans J, Huggett J, Kubista M, Mueller R, Nolan T, Pfaffl MW, Shipley GL, Vandesompele J, Wittwer CT. The MIQE guidelines: minimum information for publication of quantitative realtime PCR experiments. Clin Chem. 2009; 55:611-622.

53. Shi Y, Moura U, Opitz I, Soltermann A, Rehrauer H, Thies S, Weder W, Stahel RA, Felley-Bosco E. Role of hedgehog signaling in malignant pleural mesothelioma. Clin Cancer Res. 2012; 18:4646-4656.

54. Santoro R. Analysis of chromatin composition of repetitive sequences: the ChIP-Chop assay. Methods Mol Biol. 2014; 1094:319-328.

55. Harper JV. Synchronization of cell populations in G1/S, G2/M phases of the cell cycle. Methods Mol Biol. 2005; 296:157-166. 